\title{
Effects of hydrolyzed fish protein and autolyzed yeast as substitutes of fishmeal in the gilthead sea bream (Sparus aurata) diet, on fish intestinal microbiome
}

\author{
S. Rimoldi', E. Gini ${ }^{1}$, J. F. A. Koch², F. Iannini' ${ }^{1}$ F. Brambilla ${ }^{3}$ and G. Terova ${ }^{1 *}$
}

\begin{abstract}
Background: This study evaluated the effects of partial substitution of dietary fishmeal (FM) with either fish protein hydrolysate (FPH) or autolysed dried yeast (HiCell ${ }^{\oplus}$, Biorigin, Brazil) on intestinal microbiota of gilthead sea bream (Sparus aurata). A total number of 720 fish of $122.18 \pm 6.22 \mathrm{~g}$ were fed for 92 days with three different diets in triplicate (3 tanks/diet). A diet based on FM/vegetable meal was used as control. The other two diets were formulated by replacing FM with 5\% of either FPH or HiCell ${ }^{\circledR}$. To analyze the gut microbiota associated to autochthonous and allochthonous microbial communities, the Illumina MiSeq platform for sequencing of 16S rRNA gene and QIIME pipeline were used.
\end{abstract}

Results: A total number of 102 OTUs (operational taxonomic units) at 97\% identity were identified in fish gut samples collected at the end of feeding trial. Fourteen OTUs constituted the core gut microbiota, i.e. those OTUs found in at least nine out of fifteen samples per group and shared regardless of the diet. Eight OTUs were assigned to Firmicutes represented by Lactobacillus, Staphylococcus, and Bacillus genera, and six to Proteobacteria phylum. Dietary dried yeast autolysate modulated the intestinal microbiota by promoting the growth of some beneficial bacteria. At order level, fish fed yeast showed an enrichment in Bacillales and Clostridiales as compared to the control group, whereas fish fed FPH showed a significantly lower amount of bacteria belonging to Alteromonadales and Enterobacteriales than the other two feeding groups. Although we did not observe any effect of 5\% FM replacement with alternative nitrogen sources at phylum level, at lower taxonomical levels, the composition of gut microbiota, in terms of relative abundance of specific taxa, was significantly influenced by the dietary treatment.

Conclusions: The metabarcoding analysis revealed a clearly intestinal microbiota modulation in response to dietary autolyzed yeast. The abundance of some beneficial bacteria, i.e. indigestible carbohydrate degrading- and SCFA producing bacteria, was positively affected. Brewer's yeast autolysate could be a valid alternative protein source to FM as well as a valid functional ingredient for aquafeed production.

Keywords: Aquaculture, Gut microbiota, Fish protein hydrolysate, autolyzed yeast, Single cell proteins, fish nutrition

\footnotetext{
* Correspondence: genciana.terova@uninsubria.it

'Department of Biotechnology and Life Sciences, University of Insubria, Via

J.H. Dunant, 3, 21100 Varese, Italy

Full list of author information is available at the end of the article
}

(c) The Author(s). 2020 Open Access This article is licensed under a Creative Commons Attribution 4.0 International License, which permits use, sharing, adaptation, distribution and reproduction in any medium or format, as long as you give appropriate credit to the original author(s) and the source, provide a link to the Creative Commons licence, and indicate if changes were made. The images or other third party material in this article are included in the article's Creative Commons licence, unless indicated otherwise in a credit line to the material. If material is not included in the article's Creative Commons licence and your intended use is not permitted by statutory regulation or exceeds the permitted use, you will need to obtain permission directly from the copyright holder. To view a copy of this licence, visit http://creativecommons.org/licenses/by/4.0/ The Creative Commons Public Domain Dedication waiver (http://creativecommons.org/publicdomain/zero/1.0/) applies to the data made available in this article, unless otherwise stated in a credit line to the data. 


\section{Background}

The rapid growth of the aquaculture industry together with finite supplies of fishmeal (FM) makes it necessary to find sustainable alternative protein sources for the aquafeed sector.

Actually, various sources of protein have been considered and tested as alternative ingredients for FM. Among them, plant feedstuffs, mainly soybean meal, soybean concentrate, and grains glutens, are the most commonly used [1-3]. However, due to their amino acid imbalances, presence of anti-nutritional factors, and low palatability, a high FM replacement with vegetable meals is generally not well accepted, especially for carnivorous fish species.

In this regard, single cell proteins (SCP), including microalgae, bacteria, and yeast, represent alternative non-conventional nitrogen sources that are frequently used as feed ingredients for fish being rich in valuable and bioactive components. In particular, yeast is an environmentally friendly and sustainable ingredient due to its ability to convert low-value forest and agricultural biomass residues into high-value feed ingredients and its limited dependence on arable land, water, and climatic conditions. Yeast contains a wide range of bioactive components with potential as functional ingredients, such as $\alpha$-glucan, $\beta$-glucan, $\alpha$-mannan, nucleic acids, and antioxidants [4]. Brewer's yeast, mainly Saccharomyces cerevisiae strain, have been used as nitrogen-rich ingredient in aquaculture feeds from the beginning of the 1990s [5]. Nutritional yeasts are usually pure yeasts grown under controlled production conditions, cultivated specifically for use as a nutritional supplement and are not by-product of the brewing process [6]. However, in the last years, the increasing sensitivity for sustainable lifestyle based on circular economy is encouraging the development of new technologies to produce nutritional yeasts from low-value and non-food lignocellulosic biomass for use in aquaculture feeds [7].

To nowadays, there are several evidences of a positive effect of yeast or its cell wall components, such as mannan oligosaccharides, glucans and chitin, on fish immune system by stimulating non-specific (innate) cellular and humoral immunity $[8,9]$. However, these effects can vary depending on yeast strain, processing technology, and dietary inclusion level [7, 10, 11].

Previous studies established that protein from $S$. cerevisiae yeast can successfully replace up to $50 \%$ of fishmeal protein without negative effects on fish growth performance, whereas a dietary inclusion of up to $30 \%$ of brewer's yeast improved feed efficiency [12-14]. However, poor nitrogen digestibility, probably due to the external mannoprotein cell wall, can represent an important constraint in the use of this type of SCP in aquafeed production $[15,16]$. Furthermore, most of the nutrients present in yeast cells derive from within the cell. Therefore, several strategies have been developed to improve the digestibility of SCP products, such as by using mechanical disruption, autolysis, and enzymatic treatment [17]. Another limitation to the use of high levels of SCP in fish diets could be related to their high concentration in nucleic acids. The crude protein content of brewer's yeast is about $46.5 \%$, of which about $20 \%$ corresponds to nucleic acids (6-8\% of total composition), mostly in the form of RNA [18]. However, unlike terrestrial animals in which an excess of dietary nucleic acids is toxic leading to an increase of plasma uric acid and metabolic disorders, fish seem to tolerate high levels of nucleic acids due to their efficient hepatic uricase activity [12, 19-21].

In addition to being a source of immune-stimulating compounds, dead yeasts have prebiotic properties, too. Indeed, dietary yeast extracts have been described to have positive effects in promoting the number of beneficial bacteria and inhibiting some pathogenic bacterial species in fish [22, 23]. For example, dietary supplementation of brewer's yeast hydrolysate inhibited bacterial members of the genus Mycoplasma, and significantly increased Cetobacterium in the intestine of largemouth bass (Micropterus salmoides) [22]. However, except for a few studies, the impact of autolysed yeast on fish intestinal microbial communities is still unknown and scarcely investigated.

Accordingly, the present study aimed to investigate the effects of partial substitution of dietary fishmeal with $5 \%$ of either fish protein hydrolysate (FPH) or autolysed dried yeast $\left(\mathrm{HiCell}^{\odot}\right.$, Biorigin, Brazil) on intestinal microbiota of gilthead sea bream (Sparus aurata). The FPH is produced from fish trim waste, and its nutritive value has been demonstrated in a number of marine fish species [24-26]. FPH is rich in free amino acids, bioactive compounds, and water-soluble proteins that improve feed palatability and digestibility. $\mathrm{HiCell}^{\odot}$ is a commercial autolysed dried yeast obtained by the fermentation of a strain of Saccharomyces cerevisiae (GMO free). HiCell is suitable for animal feed use and it is assumed to have similar beneficial effects to FPH.

The high-throughput sequencing analysis of $16 \mathrm{~S}$ rRNA gene fragments was used to assess the gut bacterial community composition of fish fed with different diets.

\section{Results}

\section{Animal performance}

Detailed information on fish growth performance and feed efficiency at the end of the feeding trial, have been recently reported by Fronte et al. [27]. Briefly, no statistically significant differences were observed in mortality, fish growth rate, and feed efficiency between dietary groups after 92 days of feeding trial. 


\section{Gut microbiota composition}

The microbiota of 45 samples collected from intestine were characterized by $16 \mathrm{~S}$ rRNA gene amplicon sequencing on Illumina MiSeq platform. After data quality filtering, the run output was of 2,327,049 reads, which corresponded to an average number of $51,712 \pm 15,620$ (mean $\pm \mathrm{SD}$ ) reads per sample. A total number of 102 OTUs at $97 \%$ identity was identified in sea bream faecal samples collected at the end of the feeding trial. The Good's coverage value was > 0.99 for all dietary groups, indicating that the number of identified OTUs accounted for the entire gut microbial communities (Table 1). All sequencing data were deposited as FASTQ files in the European $\mathrm{Nu}$ cleotide Archive (EBI ENA) public database, under the accession code: PRJEB35410.

Fourteen OTUs constituted the core gut microbiota, i.e. those OTUs found in at least nine out of fifteen samples per group and shared regardless of the diet. Eight of them were assigned to Firmicutes represented by Lactobacillus, Staphylococcus, and Bacillus genera, and six to Proteobacteria phylum (Fig. 1).

The microbial community profiles of each fish were outlined at the phylum, class, order, family, genus, and species. By taking into account all samples, the microbial community comprised 7 phyla, 10 classes, 19 orders, 29 families, 40 genera, and 19 species (Please see Additional file 1). Cyanobacteria phylum, essentially represented by Streptophyta order, was dominant in all samples counting more than $85 \%$ of reads. However, Cyanobacteria phylum, along with taxa assigned to chloroplast and mitochondria, were removed from the analysis being considered plantderived sequences. After removing all eukaryotic OTUs and by considering only the most representative taxa, the overall intestinal bacterial community of sea bream consisted of 3 phyla, 5 classes, 9 orders, 12 families, 13 genera, and 4 species. The gut microbiome structure of each dietary group is shown at the

Table 1 Alpha diversity metrics of gut microbial communities in sea bream fed with three experimental diets

\begin{tabular}{llll}
\hline Items & Ctrl & $\begin{array}{l}\text { DIETS } \\
\text { FPH }\end{array}$ & AY \\
\hline Reads & $52,248 \pm 14,709$ & $49,553 \pm 17,950$ & $53,334 \pm 15,413$ \\
Observed OTUs & $53.0 \pm 4.2$ & $47.4 \pm 8.8$ & $49.0 \pm 6.1$ \\
Good's coverage & $0.99 \pm 0.00$ & $0.99 \pm 0.00$ & $0.99 \pm 0.00$ \\
PD whole tree & $6.1 \pm 0.4^{\mathrm{ab}}$ & $5.4 \pm 1.0^{\mathrm{b}}$ & $6.5 \pm 0.9^{\mathrm{a}}$ \\
Chao1 & $56.2 \pm 4.9$ & $49.6 \pm 9.4$ & $52.5 \pm 7.9$ \\
Shannon & $1.8 \pm 0.2^{\mathrm{a}}$ & $1.7 \pm 0.1^{\mathrm{ab}}$ & $1.6 \pm 0.2^{\mathrm{b}}$ \\
Simpson & $0.5 \pm 0.1$ & $0.5 \pm 0.0$ & $0.5 \pm 0.1$ \\
\hline All data are repor &
\end{tabular}

All data are reported as mean values $(n=15) \pm$ SD. Different superscript letters on the same row indicate significant differences $(p<0.05)$.

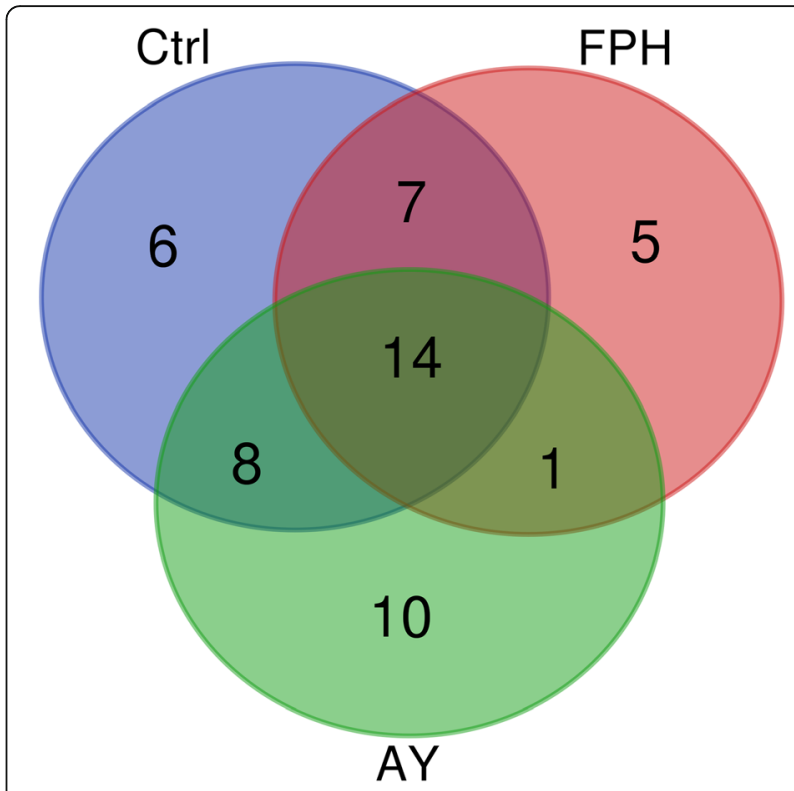

Fig. 1 Venn diagram representing unique and shared Operational Taxonomic Units (OTUs) among all three dietary groups, regardless of diet

phylum (Fig. 2), family (Fig. 3), and genus (Fig. 4) level. The taxa abundance at species level was unreliable because of the remarkable number of unassigned sequences that were found $(78-85 \%)$; therefore it was excluded from the analysis.

To calculate alpha rarefaction indices, a sequencing depth of 19,500 reads per sample was taken into account; this value corresponded to the minimum number of reads found in our samples. Among alpha diversity metrics, both phylogenetic diversity "PD whole tree index" and "Shannon diversity index" resulted significantly lower in comparison to control group in sea bream fed with $\mathrm{FPH}$ diet, but not in AY feeding group (Table 1). On the contrary, dietary fishmeal replacement with fish protein hydrolysate or autolyzed yeast did not affect species richness, which resulted quite low regardless of the diet, as indicated by "Chao 1" and "Observed OTUs" values (Table 1).

Changes in beta-diversity, i.e. between microbial communities, were found both in type (unweighted UniFrac) and abundance (weighted UniFrac) of taxa. As displayed in unweighted (Fig. 5a) and weighted UniFrac PCoA (Fig. 5b) plots, PC1 and PC2 together explained 30 and $71 \%$ of the variation between individuals, respectively. In both plots, fish fed with AY diet clearly clustered separately from the control and FPH groups (Fig. 5a, b). Outcomes of multivariate analysis were strongly validated $(p=0.001)$ by nonparametric permutation test Adonis and ANOSIM. Results of pairwise statistical analysis were summarized in Table 2. 


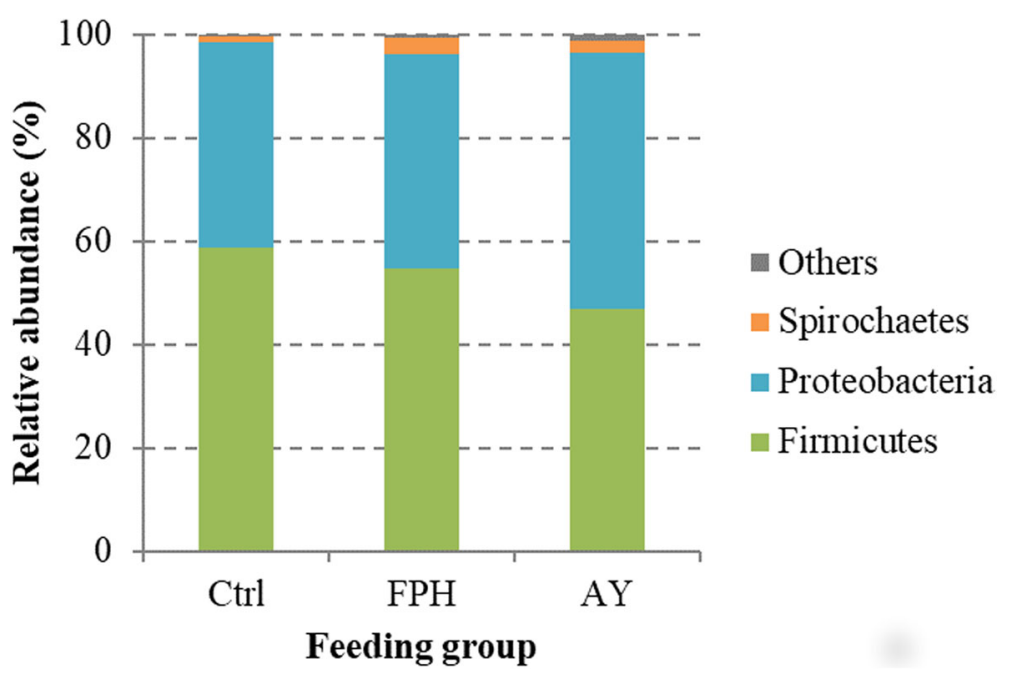

Fig. 2 Relative abundance (\%) of the overall most prevalent bacterial phyla in each dietary groups. In the figure, all taxa with an overall abundance of $\geq 1 \%$ were reported

\section{Dietary modulation of gut microbiota}

The gut microbiota of fish in the present study was mainly dominated, regardless of the diet, by three phyla: Firmicutes (41-58\%), Proteobacteria (40-49\%), and to a lesser extent Spirochaetes (1-3\%) (Fig. 2). As expected from diet formulations, which were practically equivalent in terms of vegetables and animal ingredients, Firmicutes:Proteobactera ratio was similar between the feeding groups. Although no differences were found at phylum level between feeding groups, Kruskal-Wallis analysis revealed significant changes in the relative abundance of bacteria at lower phylogenetic levels (Table 3). Major differences were found between fish fed with AY diet and control fish group. At order level, indeed, diet AY caused an enrichment in Bacillales $(p<$ $0.01)$ and Clostridiales $(p<0.05)$ in comparison to the control group, whereas fish fed with diet FPH showed a significantly lower $(p<0.001)$ amount of bacteria belonging to Alteromonadales and Enterobacteriales than the other two feeding groups (Table 3).

Diet AY was associated with an increased proportion of Prevotellaceae, Bacillaceae, Veillonellaceae families

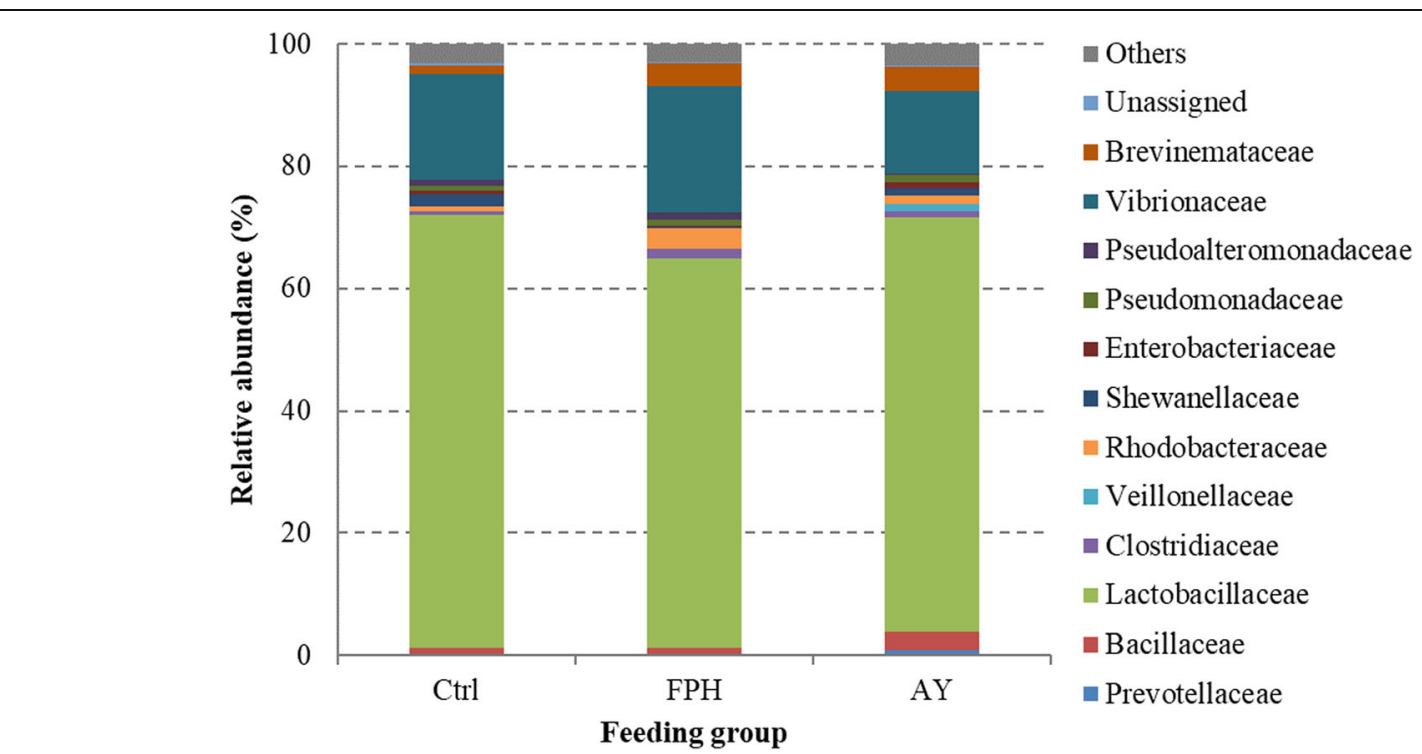

Fig. 3 Relative abundance (\%) of the overall most prevalent bacterial families in each dietary groups. In the figure, all taxa with an overall abundance of $\geq 1 \%$ were reported 


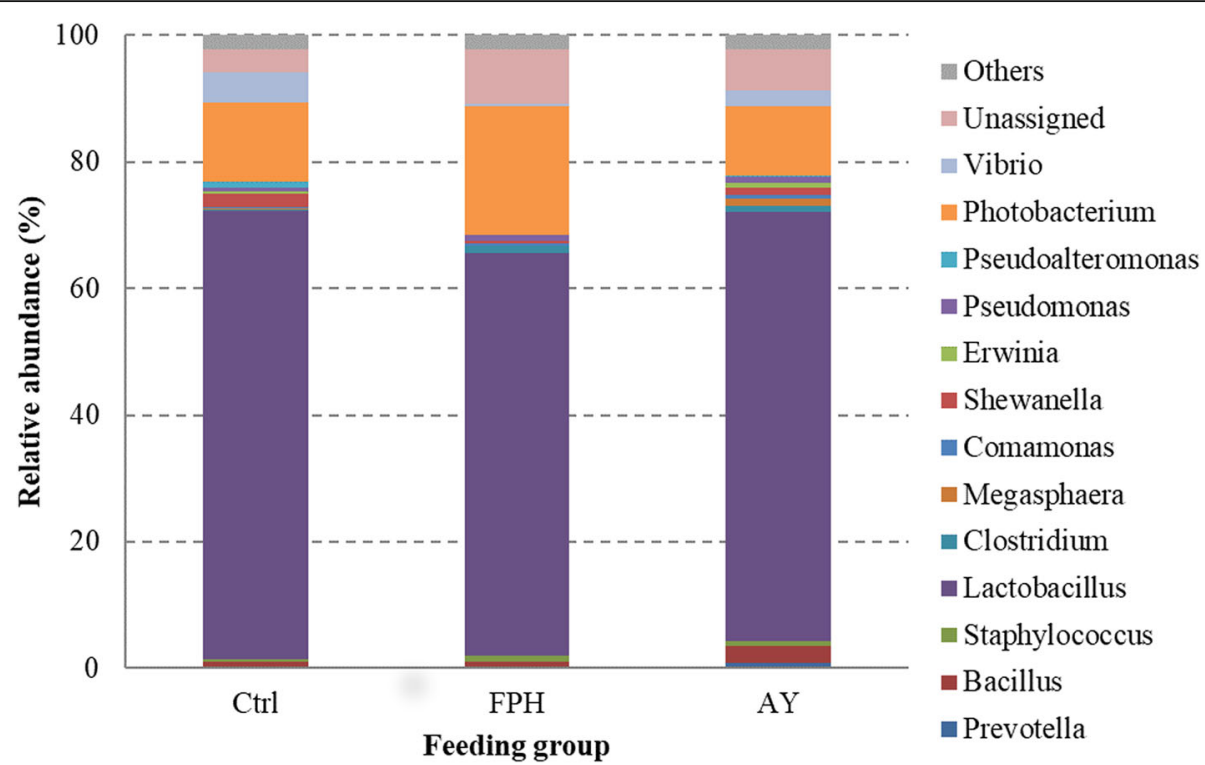

Fig. 4 Relative abundance (\%) of the overall most prevalent bacterial genera in each dietary groups. In the figure, all taxa with an overall abundance of $\geq 0.5 \%$ were reported

(Table 3, Fig. 3). Bacteria belonging to Shewanellaceae and Enterobacteriaceae families were negatively affected by dietary inclusion of hydrolysed fish protein $(p<$ 0.001). Contrariwise, irrespective of diet type, Lactobacillaceae, constituted the most abundant bacterial family (63-70\%) found in our samples (Table 3, Fig. 3). Accordingly, Lactobacillus was the most numerous genus in all dietary groups, followed by Photobacterium (1120\%), mainly represented by Photobacterium damselae species (Fig. 4). However, the most noticeable difference was that of Prevotella and Megasphera genera. In particular, they were detected only in the gut microbiota of fish fed with AY diet (Fig. 4). In the same dietary fish group, higher abundance of bacteria assigned to genus Bacillus (2.3\%) was found. Conversely, diet FHP led to a significant decrease of bacteria belonging to Shewanella genus (Table 2). Gut microbiota of fish fed with control diet, was characterized by higher percentage of Pseudoalteromonas genus than microbiota of FHP and AY dietary groups, wherein this bacterial genus resulted almost undetectable $(<0.5 \%)$ (Table 3$)$. Lastly, dietary fish protein hydrolysate supplementation caused a significant decrease $(p<0.001)$ of bacteria assigned to Vibrio genus (Table 3 ). The between-group differences were also tested to compare the mean relative abundances of individual OTUs. Statistically significant changes were mainly found between AY group and the other two feeding groups. The results of Fisher's test are reported in Additional file 2. Relative abundance of 11 OTUs was significantly influenced by the diet $(p<$ $0.05)$. Interestingly, five of them were assigned to Lactobacillus genus.

\section{Discussion}

The use of plant protein sources to replace fishmeal is a major trend in aquafeeds. However, the inclusion of plant-derived materials in the diets for carnivorous fish species is limited by their nutritional deficiencies and aminoacid imbalances, and by the presence of various antinutritional factors [28].

S. cerevisiae is the most common single cell protein source used as supplement in aquafeeds, due to its relatively high protein, energy, and micronutrient content. Furthermore, yeast is commonly non-pathogenic, free of plasmid-encoded antibiotic resistance genes and resistant to bile and acidic $\mathrm{pH}$. There are several evidences demonstrating that dietary yeasts improve fish growth performance and feed efficiency, as well as enhance gut mucosal surface in fish [29-32]. Yeast could be also considered as a functional ingredient since it contains several immune-stimulating compounds, such as $\beta$-glucans and mannanoligosaccharides, which positively influence immune responses and stress tolerance of fish $[8,9,33]$. In the present study, the replacement of FM with $5 \%$ of either FPH or yeast autolysate did not ameliorate or worsen the growth performances of sea bream. However, at the end of the feeding trial, intestine of fish fed with the $\mathrm{HiCell}^{\circ}$ (Biorigin, Brazil) supplemented diet showed a higher goblet cell density and increased nutrient absorbing area [27]. Similarly, dietary yeast hydrolysate improved the antioxidant ability and enhanced the immune response of largemouth bass (Micropterus salmoides) without any negative impact on growth [33]. 


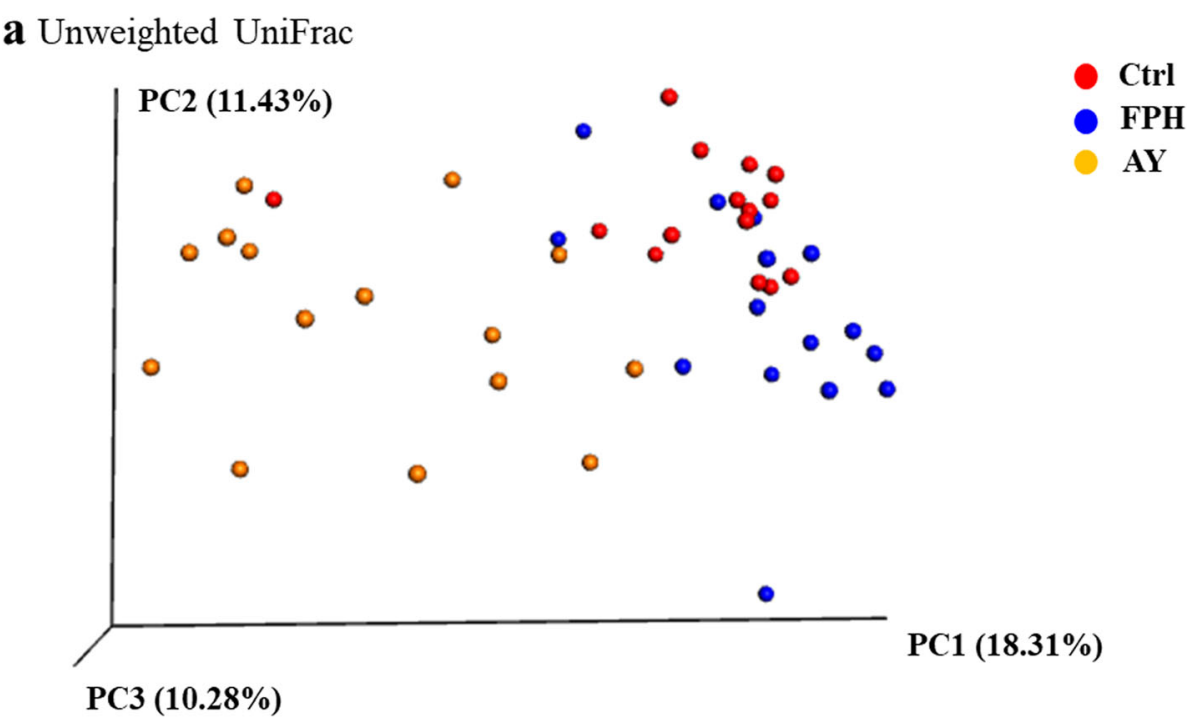

b Weighted UniFrac

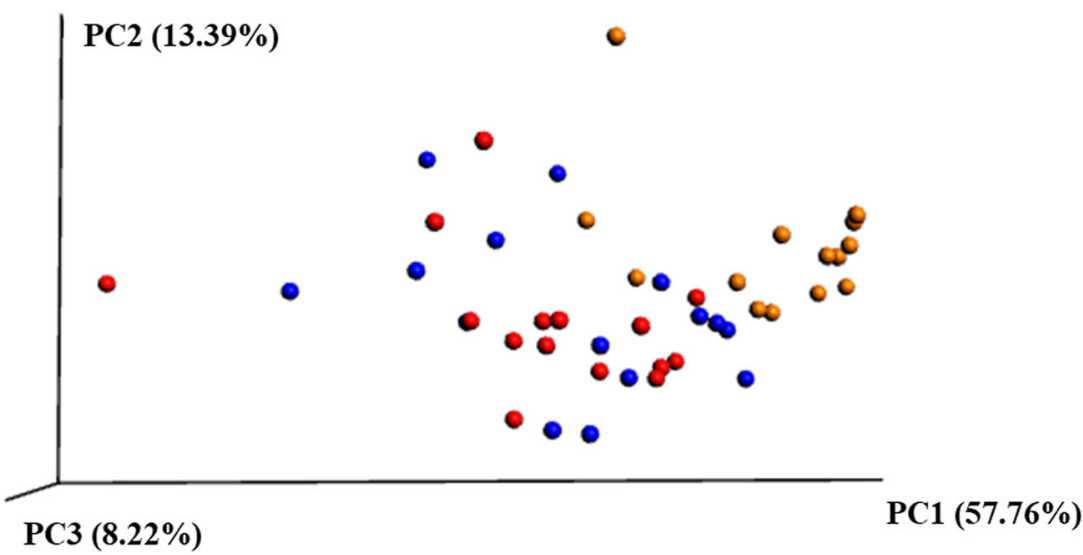

Fig. 5 Beta diversity metrics. Principal coordinate analysis (PCOA) of unweighted (a) and weighted (b) Unifrac distances of gut microbial communities associated to different diet. The figures show the 3D plot of individual fish according to their microbial profile at genus level

Table 2 Results of Analysis of similarity (ANOSIM) and permutational multivariate analysis of variance (Adonis) based on Unweighted and Weighted UniFrac distances

\begin{tabular}{lllll}
\hline \multicolumn{4}{l}{ Unweighted } & Weighted \\
\hline ANOSIM & & & & \\
& $p$ value & R value & $p$ value & R value \\
Ctrl vs FPH & $\mathbf{0 . 0 0 4}$ & 0.144 & 0.199 & 0.028 \\
Ctrl vs AY & $\mathbf{0 . 0 0 1}$ & 0.514 & $\mathbf{0 . 0 0 1}$ & 0.489 \\
FPH vs AY & $\mathbf{0 . 0 0 1}$ & 0.480 & $\mathbf{0 . 0 0 1}$ & 0.341 \\
Adonis & & & & \\
& $p$ value & $R^{2}$ & $p$ value & $R^{2}$ \\
Ctrl vs FPH & $\mathbf{0 . 0 0 1}$ & 0.08 & 0.285 & 0.04 \\
Ctrl vs AY & $\mathbf{0 . 0 0 1}$ & 0.19 & $\mathbf{0 . 0 0 1}$ & 0.38 \\
FPH vs AY & $\mathbf{0 . 0 0 1}$ & 0.18 & $\mathbf{0 . 0 0 1}$ & 0.30 \\
\hline
\end{tabular}

Significant $p$-values $(p<0.05)$ are reported in bold.
Our results clearly indicated that dietary yeast in the form of dried yeast autolysate, modulated fish intestinal microbiota by promoting the proliferation of some beneficial microorganisms. This is in line with previous studies reporting that low levels $(1-2 \%)$ of dietary brewer's yeast might affect fish intestinal microbial communities [34-36]. Indeed, when yeasts were used as live feed in rainbow trout (Oncorhynchus mykiss), there was a positive modulation of gut microbiota with an increased amount of lactic acid bacteria [29]. However, to our knowledge, the present study is the second investigation on this topic that used a high-throughput sequencing technique (i.e. Illumina MiSeq platform) and the first study on gilthead sea bream.

Results obtained from our metabarcoding analysis indicated that the most abundant phyla in sea bream intestine, regardless of the administered diet, were Firmicutes 
Table 3 Percentages of the most abundant taxa (mean \pm SEM) found in all dietary groups

\begin{tabular}{|c|c|c|c|c|c|c|c|c|c|c|}
\hline Phylum & Ctrl & & & $\mathrm{FPH}$ & & & $\mathrm{AY}$ & & & $p$-value \\
\hline Firmicutes & 58.6 & \pm & 2.9 & 54.6 & \pm & 4.3 & 41.5 & \pm & 2.9 & \\
\hline Proteobacteria & 39.7 & \pm & 3.1 & 41.5 & \pm & 4.5 & 49.4 & \pm & 2.9 & \\
\hline Spirochaetes & 1.1 & \pm & 1.1 & 3.3 & \pm & 2.8 & 2.5 & \pm & 1.2 & \\
\hline \multicolumn{11}{|l|}{ Class } \\
\hline Bacilli & 73.5 & \pm & 3.9 & 66.2 & \pm & 6.2 & 72.2 & \pm & 3.9 & \\
\hline Clostridia & 1.0 & \pm & 0.2 & 2.1 & \pm & 0.6 & 2.5 & \pm & 0.7 & \\
\hline Alphaproteobacteria & 1.2 & \pm & $0.3^{b}$ & 3.6 & \pm & $1.8^{\mathrm{b}}$ & 1.8 & \pm & $0.6^{\mathrm{a}}$ & * \\
\hline Gammaproteobacteria & 21.9 & \pm & 4.1 & 23.3 & \pm & 6.0 & 17.1 & \pm & 4.5 & \\
\hline Brevinematae & 1.5 & \pm & 1.4 & 3.8 & \pm & 3.3 & 4.0 & \pm & 1.8 & \\
\hline \multicolumn{11}{|l|}{ Order } \\
\hline Bacillales & 1.9 & \pm & $0.2^{b}$ & 2.3 & \pm & $0.4^{\mathrm{ab}}$ & 3.7 & \pm & $0.5^{\mathrm{a}}$ & $* *$ \\
\hline Lactobacillales & 71.5 & \pm & 3.9 & 63.9 & \pm & 6.1 & 68.4 & \pm & 3.6 & \\
\hline Clostridiales & $<1.0^{b}$ & & & 2.0 & \pm & $0.6^{\mathrm{ab}}$ & 2.5 & \pm & $0.6^{\mathrm{a}}$ & * \\
\hline Rhodobacterales & $<1.0$ & & & 3.3 & \pm & 1.7 & 1.3 & \pm & 0.6 & \\
\hline Alteromonadales & 2.0 & \pm & $0.5^{\mathrm{a}}$ & $<1.0^{\mathrm{b}}$ & & & 1.1 & \pm & $0.2^{\mathrm{a}}$ & $* * *$ \\
\hline nterobacteriales & 0.6 & \pm & $0.2^{\mathrm{ab}}$ & $<1.0^{\mathrm{b}}$ & & & 1.1 & \pm & $0.2^{\mathrm{a}}$ & $* * *$ \\
\hline Pseudomonadales & 0.8 & \pm & 0.2 & 1.0 & \pm & 0.2 & 1.0 & \pm & 0.2 & \\
\hline Vibrionales & 18.2 & \pm & 4.1 & 21.9 & \pm & 6.1 & 13.6 & \pm & 4.6 & \\
\hline Brevinematales & 1.4 & \pm & 1.4 & 3.8 & \pm & 3.2 & 3.9 & \pm & 1.2 & \\
\hline
\end{tabular}

\section{Family}

Prevotellaceae
Bacillaceae
Lactobacillales
Clostridiaceae
Veillonellaceae
Rhodobacteriaceae
Shewanellaceae
Enterobacteriaceae
Pseudomonadaceae
Pseudoalteromonadaceae
Vibrionaceae
Brevinemataceaeae

$\begin{array}{llll}<0.5^{\mathrm{b}} & & & \text { n.d. } \\ 1.1 & \pm & 0.2^{\mathrm{b}} & 1.2 \\ 70.9 & \pm & 3.9 & 63.6 \\ 0.5 & \pm & 0.0 & 1.6 \\ \text { n.d. } & & & \text { n.d. } \\ 0.7 & \pm & 0.3 & 3.30 \\ 2.0 & \pm & 0.5^{\mathrm{a}} & <1.0^{\mathrm{b}} \\ 0.6 & \pm & 0.2^{\mathrm{ab}} & <1.0^{\mathrm{b}} \\ 0.7 & \pm & 0.1 & 1.0 \\ 1.0 & \pm & 0.2^{\mathrm{a}} & 1.1 \\ 17.2 & \pm & 4.1 & 20.8 \\ 1.4 & \pm & 1.4 & 3.8\end{array}$

\section{Genus}

\begin{tabular}{|c|c|c|c|c|c|c|c|}
\hline Prevotella & n.d. & & & n.d. & & & 0.8 \\
\hline Bacillus & 0.9 & \pm & $0.2^{b}$ & 1.5 & \pm & $0.4^{b}$ & 2.3 \\
\hline Staphylococcus & $<0.5$ & & & 0.8 & \pm & 0.1 & 0.8 \\
\hline Lactobacillus & 70.9 & \pm & 3.9 & 63.6 & \pm & 6.1 & 67.8 \\
\hline Clostridium & $<0.5$ & & & 1.3 & \pm & 0.6 & 0.8 \\
\hline Megasphaera & n.d. & & & n.d. & & & 1.2 \\
\hline Comamonas & $<0.5$ & & & $<0.5$ & & & 0.6 \\
\hline Shewanella & 2.0 & \pm & $0.5^{\mathrm{a}}$ & $<0.5^{b}$ & & & 1.1 \\
\hline Erwinia & $<0.5^{\mathrm{ab}}$ & & & $<0.5^{b}$ & & & 0.6 \\
\hline Pseudomonas & 0.7 & \pm & 0.1 & 0.9 & \pm & 0.3 & 1.0 \\
\hline Pseudoalteromonas & 0.9 & \pm & $0.2^{a}$ & $<0.5^{\mathrm{b}}$ & & & $<0.5^{b}$ \\
\hline
\end{tabular}


Table 3 Percentages of the most abundant taxa (mean \pm SEM) found in all dietary groups (Continued)

\begin{tabular}{|c|c|c|c|c|c|c|c|c|c|c|}
\hline Phylum & Ctrl & & & $\mathrm{FPH}$ & & & $\mathrm{AY}$ & & & $p$-value \\
\hline Photobacterium & 12.4 & \pm & 4.2 & 20.2 & \pm & 5.8 & 10.9 & \pm & 4.4 & \\
\hline Vibrio & 4.7 & \pm & $1.3^{\mathrm{a}}$ & 0.5 & \pm & $0.2^{\mathrm{b}}$ & 2.5 & \pm & $0.7^{\mathrm{a}}$ & $* * *$ \\
\hline
\end{tabular}

"n.d." means not detected. Statistical significance: $\left(^{*}\right) p<0.05 ;\left(^{* *}\right) p<0.01 ;\left(^{* *}\right) p<0.001$

Different superscript letters indicate statistically significant differences (Dunn's post hoc test, $p<0.05$ )

and Proteobacteria. In line with our previous studies, these phyla usually represent up to $90 \%$ of fish intestinal microbiota in both marine, and freshwater species [3739]. Unlike the data already reported in literature about gut bacterial community of gilthead sea bream [37, 4042], Actinobacteria and Bacteriodetes were scarcely represented in our samples. This could be partly due to the high percentage of Streptophyta, deriving from undigested feed, which negatively affected the detection of other less abundant taxa. For the same reason, we cannot exclude that the species richness could be underestimated in our samples, as the expected number of OTUs is usually higher in sea bream intestine [37, 40, 41]. However, the sequencing coverage for all the dietary groups was more than $99.9 \%$ indicating that the OTUs found in our samples were representative of the sampled population.

As expected from feed formulations with similar proportion of vegetable and animal ingredients, the Firmicutes:Protobacteria ratio was comparable between dietary groups. Indeed, Firmicutes and Proteobacteria phyla are usually discriminatory for diet type being the dominance of Firmicutes more related to diets with plant ingredients than to fishmeal-based diets [39, 43-45]. Although we did not observe an overall effect of $\mathrm{HiCell}^{\circ}$ dietary supplementation on fish gut bacterial richness, the bacterial diversity in fish fed AY diet was reduced in comparison to the control group, whereas no decrease in Shannon's diversity index value was observed in fish fed with $5 \%$ of fish protein hydrolysate. In line with our study, the diversity tended to decrease with the increase of dietary brewer's yeast hydrolysate inclusion level in largemouth bass (Micropterus salmoides) [22]. Contrariwise, no significant differences in bacterial richness and diversity were found in gut microbiota of Arctic charr (Salvelinus alpinus) when $40 \%$ of dietary fishmeal was replaced with either intact or extracted yeast cells [46].

Usually a reduction in diversity is considered a negative effect as it leads to less competition for opportunistic or invading pathogens, which could thus easily colonize the gastrointestinal tract of fish [47].

Although we did not observe any effect of $5 \%$ fishmeal replacement with alternative nitrogen sources on intestinal bacterial phylum profile, at lower taxonomical levels the composition of gut microbiota, in terms of relative abundance of specific taxa, was significantly influenced by the dietary treatment. Multivariate analysis of the microbial communities showed that fish fed autolysate yeast diet clustered separately from the control group. In particular, dietary yeast led to an enrichment in bacteria belonging to Prevotellaceae, Bacillaceae, and Veillonellaceae families, whereas Lactobacillaceae, mainly represented by genus Lactobacillus, constituted the largest percentage (more than 60\%) of the intestinal microbiota of all sea bream, irrespective to the diet. This result supports the thesis that lactobacilli are part of the natural gut microbiota of several finfish species [48]. Lactic acid bacteria are generally recognised as beneficial microorganisms associated with a healthy intestine and are often used as probiotics in livestock rearing and fish culture practices; therefore, an increase in their number is considered desirable [49-51]. Indeed, it was expected that components of yeast cell wall (beta-glucans, mannan-oligosaccharides, and chitin) would have acted as prebiotics by providing favourable conditions for growth of Lactobacillus. Increased Lactobacillus levels were also found in intestine of rainbow trout and Arctic char fed a diet supplemented with a probiotic mixture of lyophilized or extracted yeast $[29,46]$. On the other hand and in line with our findings, Zhou and colleagues [22] found only little effects on the abundance of lactobacilli in intestine of largemouth bass fed a diet supplemented with brewer's yeast hydrolysate.

Interestingly, only the intestine of sea bream fed with yeast harbored members of genera Prevotella and Megasphera. Bacteria of genus Prevotella are known for their ability to degrade complex plant polysaccharides; indeed in human, these bacteria have been clearly associated to plant-based diets, which are rich in fibers $[52,53]$.

Members of Megasphaera genus are producers of short chain fatty acids (SCFAs) [54]. Acetate, propionate, and butyrate are the most abundant SCFAs in the gastrointestinal tract of fish and other vertebrates. Among the microbial-derived SCFAs, butyrate is the most important due to its several well documented positive effects on the intestinal health [55-57]. In particular, butyrate can act through both local and systemic pathways, serving as energy substrate or signaling molecule, thus affecting satiety, energy production, and storage, and exerting a number of anti-inflammatory effects [58]. Therefore, dietary modulation of SCFAs production in fish intestine should be a desirable goal. HiCell ${ }^{\circ}$ dietary inclusion seemed to promote also the growth of bacteria assigned to Bacillus genus. This genus is a member of 
Firmicutes phylum and includes both, pathogenic and beneficial bacterial species. Among probiotic candidates, Bacillus subtilis has been widely assayed in fish. Numerous studies have demonstrated that its administration enhances immune response and disease resistance [59-61].

Contrariwise, fish protein hydrolysate led to a significant decrease of bacteria belonging to Shewanella genus. Shewanella genus includes several species known to produce omega-3 fatty acids (eicosapentaenoic acid and docosahexaenoic acid) [62]. For this reason, they have been used as probiotics in fish culture practices [63, 64]. Therefore, the observed reduction of bacteria assigned to Shewanella genus in fish fed with FPH diet should be considered an adverse effect. Contrariwise, bacterial genus Pseudoalteromonas, which was well represented in gut microbiota of control fish fed with a fishmeal-based diet, could be successfully used as a probiotic in animal farming. As reported in previous studies, Pseudoalteromonas species have indeed the ability to reduce competing microbiota [65-67]. In shrimp (Penaeus vannamei), it was demonstrated that Pseudoalteromonas probiotic mechanism consists in the production of bioactive compounds with antibacterial, antifouling and antibiofilm activities [68].

In summary, this is the first metabarcoding characterization of the gut microbiome of sea bream fed with a basal diet with partial substitution of fishmeal with $5 \%$ of either fish protein hydrolysate (FPH) or commercial brewer's yeast autolysate (HiCell ${ }^{\circ}$, Biorigin). This analysis revealed a clear intestinal microbiota modulation in response to autolyzed yeast dietary inclusion. In particular, the abundance of some beneficial bacteria, i.e. indigestible carbohydrate degrading and SCFA producing bacteria, was positively affected. Therefore, this study provides the first indication that brewer's yeast autolysate could be a valid alternative to FM protein source as well as a valid functional ingredient for aquafeed production.

\section{Methods}

Feeding trial and sample collection

Details of the experimental design and feeding protocol have been recently described by Fronte et al. [27]. Briefly, the trial was set at the Experimental Center of VRM srl farm, located in Civitavecchia (Italy). A total number of 720 gilthead sea bream (Sparus aurata), purchased from the farm "Valle Ca' Zuliani", Italy (lot number SA27062015), were randomly distributed into nine circular fibreglass tanks of $2000 \mathrm{~L}$. Fish were acclimatized for 1 week under natural photoperiod and fed to visual satiety with a standard commercial diet (Naturalleva, VRM srl, Italy). After the acclimation period, fish were fed ad libitum twice per day for 92 days with three different diets in triplicate ( 3 tanks/diet). Three experimental feeds were formulated by Naturalleva VRM srl
(Cologna Veneta VR, Italy). In particular, a feed based on $\mathrm{FM} /$ vegetable meal (containing $46 \%$ crude protein and $16 \%$ fat) was used as the control diet (Ctrl). The other two feeds were formulated by replacing FM with $5 \%$ of either fish protein hydrolysate (FPH) or autolyzed yeast (AY) $\left(\mathrm{HiCell}^{\circ}\right)$ that was produced by Biorigin (Brazil) and supplied by Albitalia Srl (Milan, Italy). The proximate composition and the principal components of all tested diets are reported in Table 4.

At the end of feeding trial 15 fish/dietary group (5 fish/tank) were sacrificed and used for sample collection. For this, fish were caught and immediately euthanized with an overdose of natural clove oil containing the ingredient eugenol (Guinama S.L; Spain, Ref Mg83168). Clove oil was added at a dose of $400 \mathrm{mg} / \mathrm{l}$ to water, and premixed so that all of the oil was emulsified. Fish were then transferred to this water, loosing consciousness within seconds and ceasing breathing quickly. Since the time in which fish succumb to hypoxia and die, can vary in timescale from fish to fish, fish were left in the solution for 15 min to confirm their death. The lack of operculum movement for 15 min provided confirmation of death before disposal of the animal. Dead fish were removed with the aid of a net from the anaesthetic solution and placed on a sterile white towel on their side.

Table 4 Diet formulation and proximate composition (modified from Fronte et al. [27])

\begin{tabular}{|c|c|c|c|}
\hline & \multicolumn{3}{|l|}{ DIETS } \\
\hline & Ctrl & $\mathrm{FPH}$ & AY \\
\hline \multicolumn{4}{|l|}{ Ingredients (\% as it is): } \\
\hline Fishmeal & 22.25 & 17.80 & 17.80 \\
\hline Corn gluten meal & 17.80 & 16.91 & 17.71 \\
\hline Guar germ meal & 15.13 & 14.03 & 17.68 \\
\hline Soybean meal & 10.70 & 10.68 & 10.68 \\
\hline Soy Protein Concentrate & 9.38 & 9.79 & 10.04 \\
\hline Wheat middling & 7.45 & 8.90 & 7.12 \\
\hline Fish oil 92 & 6.93 & 6.93 & 6.93 \\
\hline Fish protein hydrolysed & & 4.60 & \\
\hline HiCell ${ }^{\circledast}$ - autolysed yeast & & & 4.60 \\
\hline Pea meal & 4.45 & 4.45 & 1.53 \\
\hline Cameline oil & 2.42 & 2.42 & 2.42 \\
\hline Mineral/Vitamin supplement & 2.00 & 2.00 & 2.00 \\
\hline Rapeseed oil & 1.49 & 1.49 & 1.49 \\
\hline \multicolumn{4}{|c|}{ Proximate composition (\% as it is): } \\
\hline Crude protein & 46.00 & 46.10 & 46.10 \\
\hline Crude fat & 16.20 & 16.10 & 16.10 \\
\hline Crude fibre & 2.10 & 2.00 & 2.20 \\
\hline Ash & 6.20 & 5.80 & 6.00 \\
\hline Gross Energy (MJ/kg) & 18.70 & 18.80 & 18.60 \\
\hline
\end{tabular}


Then, intestine was aseptically removed from each fish and the faecal matter was obtained by squeezing out and scrapping the intestinal mucosa with a sterile spatula, in order to collect both, the digesta- and the mucosaassociated microbiota (transit- and resident microbiota). The mixed faecal and gut mucosa samples were quickly transferred into a sterile Eppendorf tube containing $800 \mu \mathrm{l}$ of Xpedition ${ }^{\mathrm{Tx}}$ Lysis/Stabilization Solution (Zymo Research, Irvine, CA, USA) and then stored at room temperature, until analysis.

\section{Microbial DNA extraction}

The bacterial DNA was obtained from $200 \mathrm{mg}$ of intestinal matter by automated extraction using Cador Pathogen 96 QIAcube HT Kit and the QIAcube HT instrument (Qiagen, Italy), following the manufacturer's instructions with few modifications. The Pathogen Lysis Tubes containing samples were pre-treated by means of a TissueLyser II (Qiagen) for $2 \mathrm{~min}$ at $25 \mathrm{~Hz}$. The extracted DNA was quantified using a NanoDropTM 2000 Spectrophotometer (Thermo Scientific, Milan, Italy) and then stored at $-20^{\circ} \mathrm{C}$ until analysis.

\section{Preparation of $16 \mathrm{~S}$ amplicon library and sequencing}

The complete protocol for $16 \mathrm{~S}$ rRNA gene library preparation and sequencing has been described in Rimoldi et al. [69]. Briefly, the $16 \mathrm{~S}$ amplicon libraries were prepared using the tailed forward and reverse primer Pro341F (5'CCTACGGGNBGCASCAG-3') and Pro805R (5'-GACT ACNVGGGTATCTAATCC-3'), specific for V3-V4 region of bacterial 16S rRNA gene [70]. The expected size of PCR amplicons on Agilent 2100 Bioanalyzer trace was $\sim 550$ bp. For libraries generation, the Illumina protocol "16S Metagenomic Sequencing Library Preparation for Illumina MiSeq System" (\#15044223 rev. B) was applied. Nextera XT Index Kit (Illumina, San Diego, CA, USA) was used to incorporate two unique indexes to the $16 \mathrm{~S}$ amplicons. All indexed paired-end libraries were quantified by qPCR-based quantification using KAPA Library Quantification Kits Illumina ${ }^{\circ}$ Platforms (Kapa Biosystems Ltd., London, UK); then they were equimolar pooled for multiplexed sequencing and diluted to six picomolar. Thepooled libraries were then sequenced on an Illumina MiSeq platform (Illumina, San Diego, CA, USA) using v3 chemistry and $2 \times 300$ bp reads.

\section{Metabarcoding raw data analysis}

Metabarcoding sequencing raw data (FASTQ format) were processed using the open-source bioinformatics pipeline QIIME v1.9.1 [71], at the default setting. Detailed description of data handling has been reported in Terova et al. [38]. Briefly, FLASH v1.2.11 software (http://sourceforge.net/projects/flashpage) was used to merge the overlapping paired-end reads. In the filtering process, all the sequences whose quality score (Q) was $<30$ were discarded. A sequence similarity threshold of $97 \%$ was set to assign reads to OTUs and only the OTUs that represented at least $0.005 \%$ of total reads were retained. Greengenes database v.13.8 (http://greengenes.lbl.gov) was used as reference for taxonomy assignment. The resulting OTU tables were built using the custom script 'summarize taxa_through_plots.py'. All sequences assigned to the phylum Cyanobacteria (class Chloroplast), Rickettsiales order, and to Mitochondria family were removed from the analysis as they were considered plant contaminants.

Alpha and beta diversity statistics have been performed using QIIME scripts 'alpha_rarefection.py' and 'jackknifed_beta_diversity_.py', respectively [39]. Good's coverage, observed OTUs, Chao1 index, PD whole tree, Shannon and Simpson diversity indices were calculated. Both weighted (presence/absence/abundance matrix) and unweighted (presence/absence matrix) UniFrac beta diversity distance matrices were calculated $[72,73]$ and visualized by Principal Coordinates Analysis (PCoA). A Venn diagram displaying the core microbiome (OTUs shared regardless of the diet and found in at least nine out of the fifteen samples per dietary group) was drawn using the web tool http://bioinformatics.psb.ugent.be/ webtools/ Venn/.

\section{Statistics}

Normality and homogeneity of variance of data were checked by Shapiro-Wilk and Levene's test, respectively. To test null hypothesis $(\mathrm{p}<0.05)$, one-way ANOVA followed by Tukey-Kramer post hoc test or nonparametric Kruskal-Wallis and Dunn's post hoc test were performed depending on normality and homoscedasticity of the data. To perform statistics on microbial relative abundance data, the percentage values were firstly square root -transformed. Only those taxa with an overall abundance of more than $1 \%$ (up to family level) and $0.5 \%$ at genus level were considered for the analysis. Differential abundance analysis of OTUs between groups was performed using MetagenomeSeq ( $\mathrm{R}$ package) applying Fisher's test with False Discovery Rate (FDR) correction $(\mathrm{p}<0.05)$.

The significance of the calculated beta-diversity dissimilarities was assesed by non-parametric analysis of similarities (ANOSIM) and Adonis tests based on 999 permutations using QIIME script 'compare_categories.py'.

\section{Supplementary information}

Supplementary information accompanies this paper at https://doi.org/10. 1186/s12917-020-02335-1.

Additional file 1:. List of OTUs and corresponding number of reads found in sea bream intestine

Additional file 2:. List of OTUs significantly influenced by diet. 


\section{Abbreviations}

ANOSIM: Analysis of similarities; AY: Yeast autolysate; Ctrl: Control; FM: Fishmeal; FPH: Fish protein hydrolysed; OTU: Operational taxonomic unit; PCOA: Principal coordinate analysis; SCFA: Short chain fatty acid; SCP: Single cell protein

\section{Acknowledgments}

Special thanks to Biorigin and to VRM srl Naturalleva, which provided the functional products and diets, respectively.

\section{Author details}

"Federica lannini is a PhD student of the "Dottorato in Scienze della Vita e Biotecnologie" at the "Università degli Studi dell'Insubria", Varese, Italy."

\section{Author's contributions}

Conceptualization and methodology, G.T., S.R.; Data collection, curation and analysis, S.R., E.G. JFAK and FB; Laboratory analysis, F.I., E.G., Funding acquisition, G.T.; All authors have been involved in correcting, and commenting on the manuscript. The authors read and approved the final manuscript.

\section{Funding}

This work was funded by:

1. The EU Horizon 2020 AqualMPACT - Genomic and nutritional innovations for genetically superior farmed fish to improve efficiency in European aquaculture. Number: 818367.

2. The Italian AGER project Fine Feed for Fish (4F), Rif. No. 2016-01-01 (https://acquacoltura.progettoager.it)

The funders had no role in study design, data collection and analysis, decision to publish, or preparation of the manuscript.

\section{Availability of data and materials}

The dataset generated corresponding to the final 165 rRNA gene sequences is available in the European Nucleotide Archive (ENA), accession code PRJEB35410.

\section{Ethics approval and consent to participate}

All procedures involving fish complied with the guidelines of the European Union Council (2010/63/EU) and National legislation (DL 26/2014). The trial was set at the Experimental Center of VRM srl Naturalleva (Cologna Veneta VR, Italia), located in Civitavecchia (Italy). VRM s.r.l., is a private agri-food company that follows the EU COUNCIL REGULATION (EC) No 1099/2009 and the current consolidated version of December 14, 2019, on the protection of animals at the time of killing (Text with European Economic Area, relevance) (https://eur-lex.europa.eu/eli/reg/2009/1099/oj). The Animal Ethics Board of the VRM srl approved the protocol.

\section{Consent for publication}

\section{Not applicable.}

\section{Competing interests}

Biorigin and VRM srl provided the autolysed yeast and diets, and support in the form of salaries for authors JFAK and FB, respectively, but did not have any additional role in the study design, data collection and analysis, decision to publish, or preparation of the manuscript. This fact does not alter our adherence to BMC Veterinary Research policies on sharing data and materials.

\section{Author details}

${ }^{1}$ Department of Biotechnology and Life Sciences, University of Insubria, Via J.H. Dunant, 3, 21100 Varese, Italy. ${ }^{2}$ Biorigin Brazil. Rua XV de Novembro, 865, Lençóis Paulista, São Paulo 18680-900, Brazil. ${ }^{3}$ VRM srl Naturalleva, Via Sommacampagna, 63/D, 37137 Verona, Italy.

Received: 12 December 2019 Accepted: 6 April 2020

Published online: 22 April 2020

\section{References}

1. Gatlin DM, Barrows FT, Brown P, Dabrowski K, Gaylord TG, Hardy RW, et al. Expanding the utilization of sustainable plant products in aquafeeds: review. Aquacult Res. 2007;38:551-79.
2. Tacon AGJ, Metian M. Fishing for aquaculture: non-food use of small pelagic forage fish-a global perspective. Rev Fish Sci. 2009;17:305-17.

3. Naylor RL, Hardy RW, Bureau DP, Chiu A, Elliott M, Farrell AP, et al. Feeding aquaculture in an era of finite resources. Proc Natl Acad Sci U S A. 2009;106: 15103-10.

4. Navarrete P, Tovar-Ramrez D. Use of yeasts as probiotics in fish aquaculture. In: Sustain Aquac Tech; 2014

5. Ferreira IMPLVO, Pinho O, Vieira E, Tavarela JG. Brewer's saccharomyces yeast biomass: characteristics and potential applications. Trends Food Sci Technol. 2010;21:77-84.

6. Bekatorou A, Psarianos C, Koutinas AA. Production of food grade yeasts. Food Technol Biotechnol. 2006:44:407-15.

7. Øverland M, Skrede A. Yeast derived from lignocellulosic biomass as a sustainable feed resource for use in aquaculture. J Sci Food Agric. 2016;97: 733-42.

8. Torrecillas S, Montero D, Izquierdo M. Improved health and growth of fish fed mannan oligosaccharides: potential mode of action. Fish Shellfish Immunol. 2014;36:525-44.

9. Terova G, Forchino A, Rimoldi S, Brambilla F, Antonini M, Saroglia M. Bio$M^{\circledR}{ }^{\circledast}$ : an effective inducer of dicentracin gene expression in European sea bass (Dicentrarchus labrax). Comp Biochem Physiol B Biochem Mol Biol. 2009;153:372-7.

10. Hauptman BS, Barrows FT, Block SS, Gibson Gaylord T, Paterson JA, Rawles $\mathrm{SD}$, et al. Evaluation of grain distillers dried yeast as a fish meal substitute in practical-type diets of juvenile rainbow trout, Oncorhynchus mykiss. Aquaculture. 2014;432:7-14.

11. Sahlmann C, Djordjevic B, Lagos L, Mydland LT, Morales-Lange B, Øvrum Hansen J, et al. Yeast as a protein source during smoltification of Atlantic salmon (Salmo salar L.), enhances performance and modulates health. Aquaculture. 2019;513:734396.

12. Oliva-Teles A, Gonçalves P. Partial replacement of fishmeal by brewers yeast (Saccaromyces cerevisae) in diets for sea bass (Dicentrarchus labrax) juveniles. Aquaculture. 2001;202:269-78.

13. Li P, Gatlin DM. Evaluation of brewers yeast (Saccharomyces cerevisiae) as a feed supplement for hybrid striped bass (Morone chrysopsxM. Saxatilis). Aquaculture. 2003;219:681-92.

14. Craig SR, McLean E. The organic aquaculture movement: a role for NuProTM as an alternative protein source. In: Nutritional biotechnology in the feed and food industries. Proceedings of Alltech's 21st annual symposium. Lexington: Alltech UK; 2005. p. 285-93.

15. Rumsey GL, Hughes SG, Smith RR, Kinsella JE, Shetty KJ. Digestibility and energy values of intact, disrupted and extracts from brewer's dried yeast fed to rainbow trout (Oncorhynchus mykiss). Anim Feed Sci Technol. 1991;33:185-93.

16. Yamada EA, Sgarbieri VC. Yeast (Saccharomyces cerevisiae) protein concentrate: preparation, chemical composition, and nutritional and functional properties. J Agric Food Chem. 2005;53:3931-6.

17. Nasseri AT, Rasoul-Ami S, Morowvat MH, Ghasemi Y. Single cell protein: production and process. Am J Food Technol. 2011;6:103-16.

18. Shurson GC. Yeast and yeast derivatives in feed additives and ingredients: sources, characteristics, animal responses, and quantification methods. Anim Feed Sci Technol. November 2017;2018(235):60-76.

19. Kinsella JE, German B, Shetty J. Uricase from fish liver: isolation and some properties. Comp Biochem Physiol Part B Comp Biochem. 1985;82:621-4.

20. Rumsey GL, Kinsella JE, Shetty KJ, Hughes SG. Effect of high dietary concentrations of brewer's dried yeast on growth performance and liver uricase in rainbow trout (Oncorhynchus mykiss). Anim Feed Sci Technol. 1991;33:177-83.

21. Oliva-Teles A, Guedes MJ, Vachot C, Kaushik SJ. The effect of nucleic acids on growth, ureagenesis and nitrogen excretion of gilthead sea bream Sparus aurata juveniles. Aquaculture. 2006;253:608-17.

22. Zhou M, Liang R, Mo J, Yang S, Gu N, Wu Z, et al. Effects of brewer's yeast hydrolysate on the growth performance and the intestinal bacterial diversity of largemouth bass (Micropterus salmoides). Aquaculture. November 2017:2018(484):139-44.

23. Batista S, Ozório ROA, Kollias S, Dhanasiri AK, Lokesh J, Kiron V, et al. Changes in intestinal microbiota, immune- and stress-related transcript levels in Senegalese sole (Solea senegalensis) fed plant ingredient diets intercropped with probiotics or immunostimulants. Aquaculture. 2016;458:149-57.

24. Xu H, Mu Y, Liang M, Zheng K, Wei Y. Application of different types of protein hydrolysate in high plant protein diets for juvenile turbot (Scophthalmus maximus). Aquacult Res. 2017;48:2945-53. 
25. Khosravi S, Rahimnejad S, Herault M, Fournier V, Lee CR, Dio Bui HT, et al. Effects of protein hydrolysates supplementation in low fish meal diets on growth performance, innate immunity and disease resistance of red sea bream Pagrus major. Fish Shellfish Immunol. 2015;45:858-68.

26. Skalli A, Zambonino-Infante $J$, Kotzamanis $Y$, Fabregat R, Gisbert E. Peptide molecular weight distribution of soluble protein fraction affects growth performance and quality in European sea bass (Dicentrarchus labrax) larvae. Aquacult Nutr. 2014;20:118-31.

27. Fronte B, Abramo F, Brambilla F, De Zoysa M, Miragliotta V. Effect of hydrolysed fish protein and autolysed yeast as alternative nitrogen sources on gilthead sea bream (Sparus aurata) growth performances and gut morphology. Ital J Anim Sci. 2019;18:799-808.

28. Hardy RW. Utilization of plant proteins in fish diets: effects of global demand and supplies of fishmeal. Aquacult Res. 2010;41:770-6.

29. Adel M, Lazado CC, Safari R, Yeganeh S, Zorriehzahra MJ. Aqualase ${ }^{\circledR}$, a yeastbased in-feed probiotic, modulates intestinal microbiota, immunity and growth of rainbow trout Oncorhynchus mykiss. Aquacult Res. 2017;48:181526.

30. Salnur S, Gultepe N, Hossu B. Replacement of fish meal by yeast (Saccharomyces cerevisiae): effects on digestibility and blood parameters for gilthead sea bream (Sparus aurata). J Anim Vet Adv. 2009;8:2557-61.

31. Li P, Lawrence AL, Castille FL, Gatlin DM. Preliminary evaluation of a purified nucleotide mixture as a dietary supplement for Pacific white shrimp Litopenaeus vannamei (Boone). Aquacult Res. 2007;38:887-90.

32. Abu-Elala N, Marzouk M, Moustafa M. Use of different Saccharomyces cerevisiae biotic forms as immune-modulator and growth promoter for Oreochromis niloticus challenged with some fish pathogens. Int J Vet Sci Med. 2013;1:21-9.

33. Gong Y, Yang F, Hu J, Liu C, Liu H, Han D, et al. Effects of dietary yeast hydrolysate on the growth, antioxidant response, immune response and disease resistance of largemouth bass (Micropterus salmoides). Fish Shellfish Immunol. 2019;94:548-57.

34. Hoseinifar SH, Mirvaghefi A, Merrifield DL. The effects of dietary inactive brewer's yeast Saccharomyces cerevisiae var. ellipsoideus on the growth, physiological responses and gut microbiota of juvenile beluga (Huso huso). Aquaculture. 2011;318:90-4.

35. Burr G, Hume M, Ricke S, Nisbet D, Gatlin D. A preliminary in vitro assessment of GroBiotic-A, brewer's yeast and fructooligosaccharide as prebiotics for the red drum Sciaenops ocellatus. J Environ Sci Health B. 2008:43:253-60.

36. He S, Zhou Z, Meng K, Zhao H, Yao B, Ringø E, et al. Effects of dietary antibiotic growth promoter and Saccharomyces cerevisiae fermentation product on production, intestinal bacterial community, and nonspecific immunity of hybrid tilapia (Oreochromis niloticus female $x$ Oreochromis aureus male). J Anim Sci. 2011;89:84-92.

37. Rimoldi S, Gliozheni E, Ascione C, Gini E, Terova G. Effect of a specific composition of short- and medium-chain fatty acid 1-Monoglycerides on growth performances and gut microbiota of gilthead sea bream (Sparus aurata). PeerJ. 2018;2018:1-27.

38. Terova G, Rimoldi S, Ascione C, Gini E, Ceccotti C, Gasco L. Rainbow trout (Oncorhynchus mykiss) gut microbiota is modulated by insect meal from Hermetia illucens prepupae in the diet. Rev Fish Biol Fish. 2019;29:465-86.

39. Rimoldi S, Terova G, Ascione C, Giannico R, Brambilla F. Next generation sequencing for gut microbiome characterization in rainbow trout (Oncorhynchus mykiss) fed animal by-product meals as an alternative to fishmeal protein sources. PLoS One. 2018;13:1-29.

40. Estruch G, Collado MC, Peñaranda DS, Tomás Vidal A, Jover Cerdá M, Pérez Martínez G, et al. Impact of fishmeal replacement in diets for gilthead sea bream (Sparus aurata) on the gastrointestinal microbiota determined by pyrosequencing the 16S rRNA gene. PLoS One. 2015;10:1-22.

41. Parma L, Candela M, Soverini M, Turroni S, Consolandi C, Brigidi P, et al. Next-generation sequencing characterization of the gut bacterial community of gilthead sea bream (Sparus aurata, L.) fed low fishmeal based diets with increasing soybean meal levels. Anim Feed Sci Technol. 2016;222: 204-16.

42. Piazzon MC, Calduch-Giner JA, Fouz B, Estensoro I, Simó-Mirabet P, Puyalto $M$, et al. Under control: how a dietary additive can restore the gut microbiome and proteomic profile, and improve disease resilience in a marine teleostean fish fed vegetable diets. Microbiome. 2017;5:164.

43. Ingerslev H-C, von Gersdorff JL, Lenz Strube M, Larsen N, Dalsgaard I, Boye $M$, et al. The development of the gut microbiota in rainbow trout
(Oncorhynchus mykiss) is affected by first feeding and diet type. Aquaculture. 2014;424-425:24-34.

44. Ingerslev H-C, Strube ML, von Jørgensen LG, Dalsgaard I, Boye M, Madsen L. Diet type dictates the gut microbiota and the immune response against Yersinia ruckeri in rainbow trout (Oncorhynchus mykiss). Fish Shellfish Immunol. 2014:40:624-33.

45. Desai AR, Links MG, Collins SA, Mansfield GS, Drew MD, Van Kessel AG, et al. Effects of plant-based diets on the distal gut microbiome of rainbow trout (Oncorhynchus mykiss). Aquaculture. 2012;350-353:134-42.

46. Nyman A, Huyben D, Lundh T, Dicksved J. Effects of microbe- and musselbased diets on the gut microbiota in Arctic charr (Salvelinus alpinus). Aquac Reports. 2017;5:34-40.

47. Apper E, Weissman D, Respondek F, Guyonvarch A, Baron F, Boisot P, et al. Hydrolysed wheat gluten as part of a diet based on animal and plant proteins supports good growth performance of Asian seabass (Lates calcarifer), without impairing intestinal morphology or microbiota. Aquaculture. 2016;453:40-8.

48. Ring $\varnothing$, Hoseinifar SH, Ghosh K, Van Doan H, Beck BR, Song SK. Lactic acid bacteria in finfish-an update. Front Microbiol. 2018;9:1-37.

49. Kim S-K, Bhatnagar I, Kang K-H. Development of marine probiotics: prospects and approach. Adv Food Nutr Res. 2012;65:353-62

50. Askarian F, Kousha A, Salma W, Ringø E. The effect of lactic acid bacteria administration on growth, digestive enzyme activity and gut microbiota in Persian sturgeon (Acipenser persicus) and beluga (Huso huso) fry. Aquacult Nutr. 2011;17:488-97.

51. Ringø $\mathrm{E}$, Gatesoupe F-J. Lactic acid bacteria in fish: a review. Aquaculture. 1998;160:177-203.

52. De Filippo C, Cavalieri D, Di Paola M, Ramazzotti M, Poullet JB, Massart S, et al. Impact of diet in shaping gut microbiota revealed by a comparative study in children from Europe and rural Africa. Proc Natl Acad Sci U S A. 2010;107:14691-6.

53. Bhute S, Pande P, Shetty SA, Shelar R, Mane S, Kumbhare SV, et al. Molecular characterization and meta-analysis of gut microbial communities illustrate enrichment of Prevotella and Megasphaera in Indian subjects. Front Microbiol. 2016;7:660.

54. Tsukahara T, Koyama H, Okada M, Ushida K. Stimulation of butyrate production by gluconic acid in batch culture of pig cecal digesta and identification of butyrate-producing bacteria. J Nutr. 2002;132:2229-34.

55. Rimoldi S, Finzi G, Ceccotti C, Girardello R, Grimaldi A, Ascione C, et al. Butyrate and taurine exert a mitigating effect on the inflamed distal intestine of European sea bass fed with a high percentage of soybean meal. Fish Aquat Sci. 2016;19:1-14.

56. Terova G, Díaz N, Rimoldi S, Ceccotti C, Gliozheni E, Piferrer F. Effects of sodium butyrate treatment on histone modifications and the expression of genes related to epigenetic regulatory mechanisms and immune response in European Sea bass (Dicentrarchus Labrax) fed a plant-based diet. PLoS One. 2016;11:1-20.

57. Hamer HM, Jonkers D, Venema K, Vanhoutvin S, Troost FJ, Brummer R-J. Review article: the role of butyrate on colonic function. Aliment Pharmacol Ther. 2008;27:104-19.

58. Koh A, De Vadder F, Kovatcheva-Datchary P, Bäckhed F. From dietary fiber to host physiology: short-chain fatty acids as key bacterial metabolites. Cell. 2016;165:1332-45.

59. Cerezuela R, Fumanal M, Tapia-Paniagua ST, Meseguer J, Angel MM, Angeles EM. Changes in intestinal morphology and microbiota caused by dietary administration of inulin and Bacillus subtilis in gilthead sea bream (Sparus aurata L.) specimens. Fish Shellfish Immunol. 2013;34: 1063-70.

60. Newaj-Fyzul A, Adesiyun AA, Mutani A, Ramsubhag A, Brunt J, Austin B. Bacillus subtilis $A B 1$ controls Aeromonas infection in rainbow trout (Oncorhynchus mykiss, Walbaum). J Appl Microbiol. 2007;103:1699-706.

61. Salinas I, Cuesta A, Esteban MÁ, Meseguer J. Dietary administration of lactobacillus delbrüeckii and Bacillus subtilis, single or combined, on gilthead seabream cellular innate immune responses. Fish Shellfish Immunol. 2005;19:67-77.

62. Dailey FE, McGraw JE, Jensen BJ, Bishop SS, Lokken JP, Dorff KJ, et al. The microbiota of freshwater fish and freshwater niches contain omega-3 fatty acid-producing Shewanella species. Appl Environ Microbiol. 2016;82:218-31.

63. Cordero H, Guardiola FA, Tapia-Paniagua ST, Cuesta A, Meseguer J, Balebona $M C$, et al. Modulation of immunity and gut microbiota after dietary administration of alginate encapsulated Shewanella putrefaciens Pdp11 to 
gilthead seabream (Sparus aurata L.). Fish Shellfish Immunol. 2015;45:60818.

64. Lobo C, Moreno-Ventas X, Tapia-Paniagua S, Rodríguez C, Moriñigo MA, de La Banda IG. Dietary probiotic supplementation (Shewanella putrefaciens Pdp11) modulates gut microbiota and promotes growth and condition in Senegalese sole larviculture. Fish Physiol Biochem. 2014;40:295-309.

65. Chen WM, Lin CY, Chen CA, Wang JT, Sheu SY. Involvement of an I-amino acid oxidase in the activity of the marine bacterium Pseudoalteromonas flavipulchra against methicillin-resistant Staphylococcus aureus. Enzyme Microb Technol. 2010;47:52-8.

66. Aranda CP, Valenzuela C, Barrientos J, Paredes J, Leal P, Maldonado M, et al. Bacteriostatic anti-Vibrio parahaemolyticus activity of Pseudoalteromonas sp. strains DIT09, DIT44 and DIT46 isolated from southern Chilean intertidal Perumytilus purpuratus. World J Microbiol Biotechnol. 2012;28:2365-74.

67. Richards GP, Watson MA, Needleman DS, Uknalis J, Boyd EF, Fay JP. Mechanisms for Pseudoalteromonas piscicida-induced killing of Vibrios and other bacterial pathogens. Appl Environ Microbiol. 2017;83:e00175-17.

68. Wang H, Wang C, Tang Y, Sun B, Huang J, Song X. Pseudoalteromonas probiotics as potential biocontrol agents improve the survival of Penaeus vannamei challenged with acute hepatopancreatic necrosis disease (AHPND)-causing Vibrio parahaemolyticus. Aquaculture. 2018;494:30-6.

69. Rimoldi S, Gini E, lannini F, Gasco L, Terova G. The effects of dietary insect meal from Hermetia illucens prepupae on autochthonous gut microbiota of rainbow trout (Oncorhynchus mykiss). Animals. 2019:9:1-18.

70. Takahashi S, Tomita J, Nishioka K, Hisada T, Nishijima M. Development of a prokaryotic universal primer for simultaneous analysis of bacteria and archaea using next-generation sequencing. PLoS One. 2014;9:e105592.

71. Caporaso JG, Kuczynski J, Stombaugh J, Bittinger K, Bushman FD, Costello EK, et al. QIIME allows analysis of high-throughput community sequencing data. Nat Methods. 2010;7:335-6.

72. Lozupone C, Knight R. UniFrac: a new phylogenetic method for comparing microbial communities. Appl Environ Microbiol. 2005;71:8228-35.

73. Lozupone CA, Hamady M, Kelley ST, Knight R. Quantitative and qualitative beta diversity measures lead to different insights into factors that structure microbial communities. Appl Environ Microbiol. 2007;73:1576-85.

\section{Publisher's Note}

Springer Nature remains neutral with regard to jurisdictional claims in published maps and institutional affiliations.

Ready to submit your research? Choose BMC and benefit from:

- fast, convenient online submission

- thorough peer review by experienced researchers in your field

- rapid publication on acceptance

- support for research data, including large and complex data types

- gold Open Access which fosters wider collaboration and increased citations

- maximum visibility for your research: over $100 \mathrm{M}$ website views per year

At $\mathrm{BMC}$, research is always in progress.

Learn more biomedcentral.com/submissions 